\title{
Determinação social do processo saúde-adoecimento mental de trabalhadores rurais no Brasil
}

\author{
Maelison Silva Neves ${ }^{1}$ \\ Wanderlei Antônio Pignati ${ }^{2}$ \\ Marta Gislene Pignatti3 \\ Marcia Leopoldina Montanari Corrếa 4 \\ Universidade Federal de Mato Grosso
}

Resumo: Pesquisas sobre saúde mental de trabalhadores rurais no Brasil são rele-
vantes pela expressividade do setor agropecuário na economia nacional. Supõe-se
que os impactos do agronegócio sobre o meio ambiente, o processo de trabalho e
modos de vida no meio rural têm repercussões sobre as condições de saúde mental.
Assim, discute-se a determinação social da saúde mental de trabalhadores rurais
brasileiros, a partir de revisão narrativa da literatura. Os resultados indicaram ocor-
rência frequente de sofrimento psicológico, transtornos mentais comuns, acome-
tendo principalmente mulheres e trabalhadores temporários e maior prevalência de
suicídio em contextos rurais. Conclui-se que as pesquisas indicam a relação da into-
xicação por agrotóxicos com o surgimento de agravos à saúde mental dos trabalha-
dores rurais cujo sofrimento é intensificado pela precariedade das condições de vida,
trabalho, ausência de políticas públicas e violência no campo e contra as mulheres.

Palavras-chave: transtornos mentais; trabalho rural; agronegócio.

\footnotetext{
${ }^{1}$ Psicólogo, mestre em Educação (Unemat, 2014), doutorando do Programa de Pós-Graduação em Saúde Coletiva da UFMT. Professor Assistente do Departamento de Psicologia (UFMT).

${ }^{2}$ Médico, mestre em Saúde e Ambiente (UFMT) e doutor em Saúde Pública pela Escola Nacional de Saúde Pública da Fundação Oswaldo Cruz. Professor titular aposentado do Instituto de Saúde Coletiva da UFMT.

3 Graduada em Ecologia pela (Unesp), mestre e doutora em Saúde Coletiva (Unicamp). Professora titular aposentada do Instituto de Saúde Coletiva da UFMT.

4 Nutricionista, mestre em Saúde Coletiva, doutoranda do Programa de Pós-Graduação em Saúde Coletiva. Docente do Instituto de Saúde Coletiva (UFMT).
} 


\title{
Social determination of the mental health- disease process of rural workers in brazil
}

\begin{abstract}
Research on the mental health of rural workers in Brazil is relevant for the expressiveness of the agricultural sector in the national economy. It is assumed that the impacts of agribusiness on the environment, the work process and ways of life in rural areas have repercussions on the mental health conditions. Thus, the social determination of the mental health of Brazilian rural workers is discussed, based on a narrative review of the literature. The results indicated a frequent occurrence of psychological suffering, common mental disorders, affecting mainly women and temporary workers and a higher prevalence of suicide in rural contexts. It is concluded that the researches indicate the relationship between pesticide poisoning and the appearance of aggravations to the mental health of rural workers whose suffering is intensified by the precarious conditions of life, work, absence of public policies and violence in the countryside and against women.
\end{abstract}

Keywords: mental disorders; rural work; agribusiness.

\section{Determinación social del proceso salud-enfermedad mental de trabajadores rurales brasileños}

\begin{abstract}
Resumen: La investigación sobre la salud mental de los trabajadores rurales en Brasil es relevante para la expresividad del sector agrícola en la economía nacional. Se supone que los impactos de los agronegocios en el medio ambiente, el proceso de trabajo y los modos de vivir en las zonas rurales tienen repercusiones en las condiciones de salud mental. Así, se discute la determinación social de la salud mental de los trabajadores rurales brasileños, basada en una revisión narrativa de la literatura. Los resultados indicaron una ocurrencia frecuente de sufrimiento psicológico difuso, trastornos mentales comunes, que afectan principalmente a mujeres y trabajadores temporales y una mayor prevalencia de suicidio en contextos rurales. Se concluye que las investigaciones indican la relación entre el envenenamiento por pesticidas y la aparición de agravaciones en la salud mental de los trabajadores rurales cuyo sufrimiento se intensifica por las precarias condiciones de vida, trabajo, ausencia de políticas públicas y violencia en el campo y contra las mujeres.
\end{abstract}

Palabras clave: trastornos mentales; trabajo rural; agronegócios. 
A s relações entre saúde mental e trabalho têm sido bastante discutidas na literatura científica, em múltiplas abordagens. No setor agropecuário, os estudos que abordam o adoecimento mental dos trabalhadores investigam a relação entre sintomas, psicopatologias e seus determinantes sociais. Os resultados dessas investigações indicam a urgência de as políticas públicas voltadas para saúde, trabalho, ambiente e assistência social levarem em consideração tais determinantes como forma de reduzir os indicadores de adoecimento psíquico, sobretudo as altas taxas de suicídio (CASTRO, 2013; CASTEL, 2007; ARAÚJO, GREGGIO, PINHEIRO, 2013).

Assim, este ensaio pretende discutir a determinação 5 social do processo saúde/adoecimento mental de trabalhadores rurais brasileiros, identificando os principais processos críticos ${ }^{6}$ relacionados ao adoecimento. Busca-se responder à questão: que elementos permitem sustentar que o adoecimento psíquico, visto tradicionalmente como resultante de idiossincrasias das histórias individuais, é expressão de processos sociais estruturados conforme os modos de produção e reprodução social nas formas históricas das sociedades?

\section{Metodologia}

Para discutir a determinação social da saúde mental de trabalhadores rurais brasileiros, a partir da caracterização dos principais processos críticos, foi realizada uma revisão narrativa de literatura (RHOTER, 2007). A busca bibliográfica foi feita nas bases do MEDLINE, Scopus, Literatura de Ciências da Saúde da América Latina e Caribe, Biblioteca Virtual da Saúde e Catálogo de Teses e Dissertações da CAPES. Foram utilizados os descritores "farm workers", "rural workers", "mental health" e "mental disorders"), tornando elegíveis estudos publicados entre 2007 e 2017, que descrevessem agravos à saúde mental de trabalhadores rurais e fatores relacionados, sendo excluídos artigos de revisão ou que não permitissem distinguir o tipo de atividade produtiva e/ou categoria profissional. Após triagem com aplicação dos critérios de inclusão/exclusão, totalizou-se 36 trabalhos selecionados.

A apresentação dos resultados e discussão se divide em três seções: inicialmente, apresentamos uma caracterização das pesquisas e os principais resultados relacionados ao adoecimento psicológico dos trabalhadores rurais. Nas seções seguintes, esses resultados são discutidos a partir das relações dialéticas entre os processos globais de estruturação da sociabilidade capitalista, os processos particulares dos modos de vida e suas expressões singulares de adoecimento, finalizando com considerações que apontam uma síntese das conclusões e indicações para futuras pesquisas.

\footnotetext{
5 Na Saúde Coletiva, há uma diferença entre os conceitos de determinantes sociais da saúde e determinação social da saúde, sendo a primeira de um viés socialdemocrata e a segunda baseada em uma perspectiva anticapitalista e marxista. ${ }^{6}$ Segundo Breilh (2015: 535-536): "trabalhamos processos[críticos] que combinam a estrutura, os modos de vida dos grupos e as condições individuais de vida, e também os efeitos finais nas pessoas, mas articulando sempre as três dimensões [geral, particular, singular], compreendendo que essa unidade em movimento é a realizada, sem atomizá-la, mas mostrando os vínculos".
} 


\section{Adoecimento psicológico de trabalhadores rurais brasileiros}

Abordar o sofrimento/adoecimento psicológico é falar da experiência de outras pessoas com o mundo físico e social mediada pela corporalidade e pela linguagem. Em geral, as descrições das pesquisas sobre sofrimento psíquico baseiam-se nos relatos sobre sentimentos, emoções, visões de si, do mundo, banhados por representações do passado, presente e expectativas em relação ao futuro. Ao ficarem presas a essa descrição fenomênica dos sentidos pessoais, tais pesquisas podem ser induzidas a explicar tais estados como produções individuais do funcionamento psíquico, mesmo considerando o pano de fundo do mundo social.

Em contraposição, numa perspectiva materialista histórico-dialética, o adoecimento mental é visto numa perspectiva complexa em que os eventos individuais (história de vida, pré-disposição genética, idiossincrasias) são determinados dialeticamente pelo lugar social ocupado por esse indivíduo nas relações de produção e reprodução social da vida humana. Ou seja, apesar de ser uma experiência subjetiva, o sofrimento psicológico e os transtornos mentais têm determinações econômicas, culturais e políticas que não devem ser ignoradas pelas pesquisas e intervenções na área (BREILH, 2006, 2015).

As pesquisas abrangeram as principais regiões produtoras agropecuárias do país, com exceção da região Norte, envolvendo trabalhadores das culturas agrícolas mais representativas em termos de produtos para exportação e área plantada (PIGNATI et al., 2017): soja, cana-de-açúcar, fumo, entre outros, envolvendo tanto trabalhadores assalariados quanto agricultores familiares. Além desses, foram encontradas pesquisas dos setores de café, feijão, hortifrutigranjeiros e policultura, conforme Quadro 1.

Os principais agravos à saúde mental dos trabalhadores rurais foram estresse físico e psicológico, depressão, ansiedade, transtornos mentais comuns, suicídio e sofrimento social/difuso. Chama atenção a elevada prevalência de transtornos mentais comuns entre os trabalhadores de todos os cultivos, principalmente do fumo e de hortifrutigranjeiros, que ultrapassaram os 50\% da amostra (CEZARVAZ, BONOW, SILVA, 2015; CEZAR-VAZ et al., 2016), assim como os casos de suicídio (KRAWCZYK et al., 2017; MEYER et al., 2010), sugerindo que a população rural e trabalhadores agrícolas são os sujeitos mais vulneráveis. As mulheres foram identificadas como as mais atingidas pelos Transtornos Mentais Comuns (TMC) e os homens maiores vítimas de suicídio.

Seguindo a hipótese desse artigo, continua-se a discussão expondo o quanto as modificações estruturais no campo brasileiro, impulsionadas pela modernização conservadora, modificaram os modos de vida dos grupos (relações de trabalho e cotidiano) e afetaram as condições de vida dos indivíduos, produzindo vulnerabilidades aos trabalhadores rurais. 
Quadro 1 - Caracterização dos estudos quanto ao tipo de cultivo, estados, categoria de trabalhadores temas e metodologia

\begin{tabular}{|c|c|c|}
\hline $\begin{array}{l}\text { Cultivol } \\
\text { Estados }\end{array}$ & Estudos $^{7}$ & Estudos e Eixos temáticos \\
\hline $\begin{array}{l}\text { Cana (AL, GO, } \\
M G, M S, S P)\end{array}$ & $\begin{array}{ll}\text { 1. } & \text { ALMUSSA }(2011) \\
\text { 2. } & \text { COSTA }(2015) \\
\text { 3. } & \text { DUARTE }(2010) \\
\text { 4. } & \text { FAKER }(2009) \\
\text { 5. } & \text { FARIA }(2012) \\
\text { 6. } & \text { FRANCO-BENATTI (2016) } \\
\text { 7. } & \text { GALIANO (2010) } \\
\text { 8. } & \text { PRIULI et al. (2014) } \\
\text { 9. } & \text { VERÇOSA }(2016) \\
\end{array}$ & $\begin{array}{l}\text { - Saúde, trabalho, qualidade de vida, condições de } \\
\text { vida e transtornos mentais comuns: } 1,3,4,9 \\
\text { - Trabalho rural, migrações e saúde: } 2,7 \\
\text { - Trabalho rural no período de safra, estresse e sa- } \\
\text { úde: } 8 \\
\text { - Reestruturação produtiva no setor rural e saúde } \\
\text { mental: } 5 \\
\text { - Implicações dos acidentes de trabalho para saúde } \\
\text { mental: } 6\end{array}$ \\
\hline $\begin{array}{l}\text { Grãos } \\
\text { PR, SC, RS } \\
\text { MG, ES, SP, } \\
\text { BA, MT, MS, } \\
\text { GO }\end{array}$ & $\begin{array}{ll}\text { 10. } & \text { CHRISMAN (2012) } \\
\text { 11. } & \text { CONTI et al. }(2017) \\
\text { 12. } & \text { GUIMARÃES }(2007) \\
\text { 13. } & \text { LIMA (2010) } \\
\text { 14. } & \text { MORIN }(2016) \\
\text { 15. } & \text { SANTOS }(2013) \\
\end{array}$ & $\begin{array}{l}\text { - Suicídio entre trabalhadores rurais: } 10 \\
\text { - Trabalho rural, Qualidade de vida e saúde/adoeci- } \\
\text { mento mental: } 11,13,15 \\
\text { - Vivências de bem-estar e mal-estar de trabalhado- } \\
\text { res na produção agrícola:12 } \\
\text { - Transtornos mentais e Agrotóxicos: } 14 \\
\end{array}$ \\
\hline $\begin{array}{l}\text { Hortifruti- } \\
\text { granjeiros } \\
\text { MG, RS, SP, } \\
\text { RJ, SE }\end{array}$ & $\begin{array}{l}\text { 16. } \text { ARAÚJO et al. (2013) } \\
\text { 17. CEZAR-VAZ et al. (2016) } \\
\text { 18. GIONGO (2013) } \\
\text { 19. } \text { MEYER et al. (2010) } \\
\text { 20. PAZ DE LIMA (2008) } \\
\text { 21. PAZ DE LIMA (2014) }\end{array}$ & $\begin{array}{l}\text { - Agrotóxicos e saúde/adoecimento mental no con- } \\
\text { texto rural: } 16,17,20 \text { e } 21 \\
\text { - Transtornos de humor, Suicídio e exposição agro- } \\
\text { tóxicos: } 19 \\
\text { - Sofrimento Social na suinocultura: } 18\end{array}$ \\
\hline $\begin{array}{l}\text { Policultura } \\
\text { RN, BA, RS, } \\
\text { MT }\end{array}$ & $\begin{array}{ll}\text { 22. } & \text { COSTA }(2014) \\
\text { 23. } & \text { FAVERO }(2012) \\
\text { 24. } & \text { PINHEIRO }(2016) \\
\text { 25. } & \text { PISTÓRIO }(2017) \\
\text { 26. } & \text { POLETTO }(2009) \\
\text { 27. } & \text { TONET }(2015) \\
\text { 28. } & \text { WERLANG }(2013) \\
\end{array}$ & $\begin{array}{l}\text { - Gênero, trabalho e saúde mental: } 22,27 \\
\text { - Impacto psicossocial da seca: } 23 \\
\text { - Agrotóxicos, conflitos no campo e sofrimento so- } \\
\text { cial: } 24,25 \\
\text { - Processo de trabalho rural e saúde mental: } 26 \\
\text { - Suicídio e sofrimento social no meio rural: } 28\end{array}$ \\
\hline $\begin{array}{l}\text { Fumo } \\
\text { RS }\end{array}$ & $\begin{array}{l}\text { 29. } \text { CAMPOS et al. (2016) } \\
\text { 30. CARGNIN (2013) } \\
\text { 31. CASTRO (2013) } \\
\text { 32. CEZAR-VAZ et al. (2015) } \\
\text { 33. CRUZ (2014) } \\
\text { 34. FARIA et al. (2014) } \\
\text { 35. FARIA, FASSA, MEUCCI } \\
\text { (2014) } \\
\text { 36. MOURA (2016) }\end{array}$ & $\begin{array}{l}\text { - Suicídio entre trabalhadores rurais: } 33,28,36 \\
\text { - Condições de vida, Processo de trabalho e saúde: } \\
\text { 30, } 31,34,35 \\
\text { - Trabalho, gênero e saúde mental: } 32 \\
\text { - Exposição a agrotóxicos e transtornos mentais: } 29 \text {, } \\
34 \text { e } 35\end{array}$ \\
\hline
\end{tabular}




\section{Acumulação capitalista e modernização conservadora no campo como dimensão estruturante do adoecimento mental de trabalhadores rurais}

O processo de produção no setor agropecuário brasileiro que caracteriza as últimas décadas sofreu profundas transformações oriundas da reestruturação produtiva, principalmente nos "elementos técnicos e sociais da estrutura agrária, sobretudo na base técnica de produção, nas relações sociais de produção e na estrutura fundiária" (ELIAS, 2015: 26). No âmbito da agricultura, esse processo se expressa pela forma do agronegócio globalizado, no qual a produção agropecuária passa a responder às demandas do mercado internacional e não às necessidades locais, tornando os alimentos em commodities, nos quais as regiões produtivas tornam-se apenas regiões do fazer, sem nenhum controle ou soberania sobre o processo produtivo (ELIAS, 2015; MONTANARI CORRÊA, 2019).

Segundo Bühler, Guibert e Oliveira (2016), na América do Sul, esse processo foi intensificado a partir dos anos 2000 pela incorporação de investidores estrangeiros e especulação financeira, expansão rápida das áreas produtivas, aumento de demandas e conflitos por recursos naturais (terra e água), além de intensificação da incorporação de recursos tecnológicos para incrementar o processo produtivo (mecanização, utilização de agrotóxicos e outros produtos químicos, sementes e mudas transgênicas), o que ocasiona profundas mudanças no processo de trabalho, meio ambiente e modos de vida das populações.

Desse modo, as transformações ocorridas no processo produtivo do campo, sob a forma de acumulação dos monopólios internacionais, caracterizam-se por pressões para substituição da agricultura campesina e formas tradicionais de agricultura pela penetração agressiva da agroindústria e seus pacotes tecnológicos de mecanização, uso intensivo de agrotóxicos e sementes transgênicas, gerando pressões sobre os territórios indígenas e comunidades tradicionais, modificando profundamente os modos de vida comunais, substituindo-os pela forma de organização social e produtiva ordenada pelas lógica de competência produtivista, monocultura de exportação, destruindo as formas tradicionais de produção agrícola comunitária e os conhecimentos ancestrais de convívio não predatório com a natureza.

Desse modo, os elementos estruturais comuns a todos os contextos produtivos agrícolas verificados nessa revisão são o desenvolvimento desigual, gerando pobreza para uns e riqueza para poucos; concentração fundiária, com respectivos conflitos de terra; mudanças nos perfis produtivos com elevado custo humano e ambiental, alterando modos de vida e produzindo impactos ambientais que atingem os mais pobres, com destaque para o uso indiscriminado de agrotóxicos, sementes transgênicas e continuidade de condições precárias do trabalho manual.

Além disso, o Estado tem apresentado um papel ambíguo: precariedade ou ausência de fiscalização e controle sobre o uso dos agrotóxicos, as condições de trabalho, além de ausência ou ineficiência de políticas sociais para a população rural, ao mesmo tempo em que implementa a flexibilização das relações de trabalho, mostrando-se ainda negligente na eliminação da remuneração por produção. Essas condições estruturais globais do processo de produção e reprodução social condicionam as formas históricas de sociabilidade humana, incluídos os processos estruturantes e generativos das condições de saúde/adoecimento das populações e a "vida psíquica", como veremos mais detalhadamente a seguir. 


\section{Processos críticos do adoecimento mental de trabalhadores rurais: trabalho, sociabilidade e subjetividade}

Levando em consideração o quadro sintomático do adoecimento mental descritos nas pesquisas brasileiras, a categoria sofrimento foi predominante em todos os contextos, principalmente com afetos ligados à insegurança, medo, sentimento de desvalor, depressão, ansiedade, cansaço, humilhação, solidão, tensão, ideação suicida. Um olhar voltado apenas para os sintomas e diagnósticos não permitiria diferenciar as especificidades das histórias de vida de cada um desses sujeitos, misturados a uma pintura confusa dos quadros nosográficos que muitas vezes limitam a terapêutica ao nível do cuidado psicoterápico e medicamentoso, escamoteando processos sociais e históricos alienantes e atrelados à exploração e expropriação do trabalhador (LEÃO e GOMEZ, 2014).

Quando se analisam os dados das pesquisas numa perspectiva da complexidade proposta pela epidemiologia crítica, verifica-se o nexo dos fenômenos biopsicológicos como uma processualidade histórica atravessada pelos contextos econômicos, sociais e culturais no âmbito da sociabilidade capitalista. Desse modo, torna-se possível apreender o adoecimento mental desses trabalhadores nas múltiplas dimensões e níveis multiescalares da reprodução da vida biológica e social e suas pressões sobre as condições biopsíquicas dos trabalhadores. Para isso, selecionou-se alguns elementos apontados como centrais: Processos de exploração na organização do trabalho; Precariedades nas condições estruturais da vida e prejuízos relacionados a eventos climáticos (seca, geada, granizo, enchentes); Iniquidades de gêneros e raciais; Expropriações, degradação ambiental e violência no campo; e Imposição aos agrotóxicos. Destacam-se esses fatores por se apresentarem como os principais mediadores entre as condições globais de estruturação da vida e trabalho no campo e as condições psíquicas dos trabalhadores, nos estudos revisados, de modo que não podem ser vistos de forma isolada, mas enquanto processos sinérgicos subsumidos à sociabilidade capitalista.

\section{Processos de exploração na organização do trabalho}

As pressões geradas pela forma capitalista de produção de valor a partir da exploração dos recursos naturais e da força de trabalho para comercialização de commodities tem sido o principal fator global estruturante dos processos que favorecem o adoecimento psicológico de trabalhadores rurais (WERLANG, 2009).

No âmbito dos assalariados e/ou temporários, destacam-se os cortadores de cana, cujos processos críticos se relacionam sobretudo ao surgimento de novos riscos ocupacionais relacionados com a inserção de maquinário no processo produtivo, incluindo divisão do espaço de trabalho (manual) com máquinas pesadas; condições de trabalho insalubres, penosas, precarizadas (ALMUSSA, 2011; RUMIN, NAVARRO e PERIOTO, 2008).

Além da carga física, as pressões psicossociais tais como o excesso de controle sobre as atividades, assédio moral, pouco tempo para descanso, poucos espaços de socialização, estímulo à competitividade entre colegas que esgarça as relações interpessoais, ameaça de demissão aos "improdutivos" e premiação dos trabalhadores "produtivos" (COSTA, 2015; FRANCO-BENATTI, 2016) são elementos geradores de desgaste. Os baixos rendimentos do trabalho, o pagamento por produção, a ameaça do desemprego, os mecanismos sociais de intensificação do trabalho (uso de drogas e substâncias químicas que prolongam a resistência), fazem 
com que o trabalhador se esforce além de suas condições biológicas de resistência, forçando-se a "ignorar" os riscos e sinais corporais, evitando recorrer a afastamento do trabalho para recuperação psicobiológica (ALMUSSA, 2011; FRANCO-BENATTI, 2016; VERÇOZA, 2015; RUMIN, NAVARRO e PERIOTO, 2008).

Os trabalhadores também relatam a humilhação de ter que se submeter a uma série de protocolos do INSS para depois receber uma negação de direitos em casos de adoecimento por não reconhecerem o nexo entre adoecimento e trabalho, colocando-os em situação de desamparo: não se sentem em condições de trabalhar e não têm recursos para garantir sua subsistência (FRANCO-BENATTI, 2016).

Condições semelhantes são descritas entre os trabalhadores assalariados nas culturas de grãos (feijão e café) e hortifrutigranjeiros: precariedade das relações de trabalho, empregos temporários/sazonais predominante entre as mulheres, que acumulam o trabalho doméstico; longo tempo de risco de desemprego (entressafra do café); trabalho árduo, braçal, ausência ou precariedade de equipamentos de proteção, remuneração por produção, organização taylorista com intensificação do ritmo de trabalho, postura incômoda e lesiva durante as atividades, movimentos repetitivos dos membros superiores e elevada exigência de esforço físico, o que acaba demandando esforços cognitivos e afetivos, em termos de disposição emocional, boa vontade, estado de humor (GUIMARÃES, 2007; LIMA et al., 2010, PAZ DE LIMA, 2015, 2008).

Entre fumicultores gaúchos e suinocultores catarinenses, proprietários das terras onde trabalham, destaca-se a perda de controle da organização do trabalho que passa a responder às metas de qualidade e produtividade das indústrias com as quais têm contrato de fornecimento de matérias primas (CASTRO, 2013; GIONGO, 2013). Assim, suas condições de trabalho reproduzem relações assalariadas, nas quais o ritmo, a carga de trabalho e a valoração do produto do trabalho são definidos exteriormente e seguem regras estranhas a esses trabalhadores. $\mathrm{O}$ pagamento é feito ao final do processo produtivo e depende da avaliação de qualidade feita unilateralmente pela indústria, gerando mecanismos de exploração mediante pagamento aquém do que os produtores esperaram, gerando, inclusive, endividamento, frustração, sensação de humilhação e exploração.

No estudo de Costa (2014), os aspectos deteriorantes da organização do trabalho se relacionam a problemas de assistência técnica e crédito agrícola, que penalizam o processo produtivo, além das instabilidades climáticas relacionadas à seca e infraestrutura de transporte precária para escoamento da produção, mesmo para as cidades próximas. Pistório (2017) descreve que as mesmas dificuldades relacionadas à precariedade de assistência técnica e trabalho físico desgastante estão presentes, mas o adoecimento é atenuado por conta da possibilidade de maior controle sobre o processo de trabalho

Em comum, destaca-se a pouca efetividade das políticas públicas voltadas para o desenvolvimento de produção e melhoria das condições de vida dessa população (SANTOS, 2013; ARAÚJO, GREGGIO E PINHEIRO, 2013), como a negligência dos gestores públicos quanto à assistência e implementação da política nacional de diversificação de cultivos para os produtores de fumo (CARGNIN, 2013), ausência de parâmetros legais de proteção para o agricultor familiar inserido nas cadeias produtivas industriais como fornecedor de matéria-prima (SANTOS, 2013; CASTRO, 2013; GIONGO, 2013), dificuldades no acesso aos direitos 
previdenciários (CASTRO, 2013; GIONGO, 2013) e também de proteção às mulheres trabalhadoras, negando, inclusive, o reconhecimento de suas atividades de trabalho (COSTA, 2014; TONET, 2015).

\section{Precariedades nas condições estruturais da vida e prejuízos relacionados a eventos climáticos}

A histórica expropriação e concentração de terras nas mãos de uma elite agrária faz com que reste aos trabalhadores apenas a venda de sua força de trabalho ${ }^{8}$ em ocupações precárias, vivenciando desvalorização social motivada pelo analfabetismo ou baixa escolaridade e ausência de qualificação profissional. Para muitos desses, o desemprego em suas regiões de origem restringe as possibilidades de subsistência, levando-os a migrarem para os grandes polos produtivos do agronegócio em busca de trabalho formal e com expectativas de melhoria de suas condições de vida, porém encontram péssimas condições de habitação nos alojamentos, trabalho intenso e desgastante (ARAÚJO, GREGGIO e PINHEIRO, 2013; COSTA, 2014; FARIA et al., 2015; LIMA et al., 2010; RUMIN et al., 2008; FARIA, 2012; FAKER, 2009; PAZ DE LIMA, 2008; 2014).

Dentre esses, destacam-se os trabalhadores do corte de cana cuja maioria são oriundos do Nordeste, vivendo longe da família, em bairros periféricos, marcados pela violência e falta de infraestrutura, ganho insuficiente para atender todas as necessidades da família, sofrendo situações de discriminação e desvalorização social por conta de sua origem nordestina, sendo tratados como "eternos retirantes" (DUARTE, 2012; COSTA, 2015; GALIANO, 2010).

Por outro lado, mesmo para aqueles que trabalham na própria terra, fruto de muita luta por assentamento rural, não é fácil produzir/reproduzir a vida sem assistência técnica, financiamento para aquisição de insumos e equipamentos, o que torna o trabalho lento, pesado, desgastante. Destaca-se ainda as dificuldades no escoamento da produção, com estradas ruins e vivendo em locais onde estão distantes as políticas de atenção à saúde, educação, transporte, saneamento básico, sem falar da continuidade da violência e pressões do latifúndio para que abandonem as terras, com a omissão ou até contribuição de agentes do estado, vivendo assim em constante estado de tensão psicológica (PINHEIRO, 2016; PISTÓRIO, 2017; SANTOS, 2013; COSTA, 2014).

As questões climáticas também apresentam dificuldades globais do processo produtivo que se relacionam com surgimento de sofrimento, principalmente a escassez de recursos hídricos, exposição a condições de seca ou granizo, gerando vulnerabilidade psicossocial e perdas financeiras (SANTOS, 2013; FAVERO, 2012; CASTRO, 2013).

\section{Iniquidades de gêneros e raciais}

À precariedade das condições estruturais de vida e de trabalho, somam-se as mazelas das relações sociais marcadas pela violência de gênero e racial. A maior frequência de dores, desgaste físico, problemas do sono e transtornos mentais comuns entre as mulheres (CEZAR-VAZ et al., 2015; FARIA et al., 2014; POLETTO, 2009; DUARTE, 2010) produz-se socialmente nas relações hierarquizadas e de dominação, no menor tempo para repouso e limitação maior nas margens de

${ }^{8}$ Marx (2011) discute a matriz histórica desse processo no âmbito da formação social capitalista, denominado por ele como acumulação primitiva. Os processos descritos por ele ainda se assemelham bastante com o modo como se expressa a questão agrária no Brasil contemporâneo e suas bases históricas podem ser aprofundadas em Fernandes (1975). 
escolha de gestão da própria vida, visto que acumulam o trabalho na lavoura, o trabalho doméstico e o cuidado dos filhos, sem participação nas decisões sobre a produção ou sobre os rumos políticos da comunidade, e sem reconhecimento nem remuneração correspondente (COSTA, 2014). A situação não é diferente para aquelas que vendem sua força de trabalho: resta-lhes o trabalho mais precário, desgastante, temporário e mal remunerado, acumulando a mesma sobrecarga e violência no contexto da vida doméstica, com intensificação de exigências físicas e mentais (LIMA, 2009; ARAÚJO; GREGGIO; PINHEIRO, 2013).

A precarização da relação de trabalho, baseada no trabalho informal e sazonal, envolvendo remuneração por diárias (fruticultura) ou por produção (cana, café), realizado predominantemente por mulheres, sendo intensificado em período de colheita demonstraram relação com maior frequência de quadros de depressão, distúrbios do sono, estresse em fase de exaustão e ocorrência de transtornos mentais comuns (LIMA et al., 2010; PRIULLI et al., 2014).

Desde a "abolição da escravatura", aos negros foi negada a possibilidade de sobreviver com o cultivo da terra por conta da promulgação da Lei de Terras. Tal lei determinava que somente poderia receber terras do Estado os cidadãos afortunados, o que impedia que os negros brasileiros pudessem tirar da terra a possibilidade de garantir sua própria sobrevivência, sendo empurrados para formas de trabalho precário e degradante e vivendo nos bolsões de miséria que darão origem às favelas das grandes cidades.

Assim, na formação social brasileira escravista, os negros foram considerados sujeitos de segunda classe, sub-humanidade subalternizada e impedida de desenvolvimento pleno de suas potencialidades (ALVES, JESUS e SCHOLZ, 2015). Tal processo social de segregação continua sob a forma disfarçada de preconceito contra o nordestino nas regiões produtoras do agronegócio, onde são considerados “cidadãos" de segunda classe, preguiçosos, apesar de serem eles os grandes heróis do processo de produção social da riqueza, da qual são alijados (DUARTE, 2010; FRANCO-BENATTI, 2016). Para Dussel (1993), esse é um elemento fundante da modernidade (e também da sociabilidade capitalista), no qual o europeu (e o capitalista), para se firmar como conquistador, bem-sucedido, empreendedor, cidadão de posses, precisa negar e encobrir o Outro.

\section{Expropriações, degradação ambiental e violência no campo}

A violência no contexto agrário brasileiro é secular: foi inaugurada com a chegada dos colonizadores, tendo a primeira missa e o batismo de terra de Santa Cruz como um dos marcos da violência simbólica que também se tornaria física com o extermínio dos povos indígenas e escravização dos povos africanos. Mais de quinhentos anos depois, o processo colonizador mudou de forma, atrelou-se à lógica de acumulação capitalista, mas continua com as mesmas práticas: expropriação dos povos originários e tradicionais de suas terras e da possibilidade de viver de seu próprio trabalho mediante agricultura, pesca e extrativismo. Conforme Virgínia Fontes (2010: 88), a expropriação é uma das condições necessárias para a reprodução da sociabilidade capitalista, não se restringindo à forma de exploração econômica do trabalho, mas submetendo o conjunto da sociabilidade humana à "supressão de meios de existência ao lado da mercantilização crescente dos elementos necessários à vida”.

Nos estudos revisados, Pinheiro (2016) e Pistório (2017) apresentam reflexões sobre a violência, explícita ou velada, imposta pelo latifúndio e agronegócio aos pequenos produtores rurais. Em investigação com trabalhadores assentados 
na Bahia, em região de conflito agrário com as produtoras de celulose, Pinheiro (2016) constata que os trabalhadores relacionam a tensão psicológica que vivem com as expulsões sofridas, por medidas de reintegração de posse feita de forma violenta e a destruição de suas plantações com máquinas operadas a mando das empresas de celulose. Em um dos depoimentos registrados por Pinheiro (2016), uma trabalhadora descreve indignação pelo fato de o governo estadual reconhecer que importam farinha, enquanto recorda da destruição de suas plantações de mandioca.

Além da expropriação da terra, Pinheiro (2016: 207) descreve outra forma de expropriação que resulta em alienação do trabalhador rural: "deslocamento do controle das tecnologias do processo produtivo para a o domínio das empresas capitalistas que monopolizam o controle do conhecimento técnico-científico e se utilizam de estruturas do Estado para normatizar as práticas e modelar as formas de produção na agricultura".

Pistório (2017) descreve o processo de sofrimento social de pequenos produtores na luta pela posse da terra em uma região mato-grossense dominada pelo latifúndio produtor de soja, milho e algodão. A decisão desses trabalhadores de ocupar uma terra improdutiva para não mais vender sua força de trabalho para as grandes fazendas e/ou viver da própria terra, retomando o modo de vida campesino (nas palavras da autora, na "contracorrente do agronegócio"), produziu reação dos latifundiários que tentaram boicotar por meio de ameaças, judicialização e difamação. À incerteza de garantia do direito à terra, falta de estrutura e assistência técnica necessários à produção camponesa, além das barreiras ao financiamento público juntam-se à tensão do conflito pelo direito à terra numa luta contra "gigantes" do latifúndio atrelado ao capital monopolista do agronegócio.

\section{Imposição aos agrotóxicos}

O Brasil é o país que mais utiliza agrotóxicos no mundo. Segundo Pignati et al. (2017), em 2015 foram plantadas 71,2 milhões de hectares com utilização de aproximadamente 900 milhões de litros de agrotóxicos. Dentre os produtos cultivados destacam-se a soja, milho e cana-de-açúcar, que juntos perfazem $72 \%$ da área plantada e $82 \%$ de volume de agrotóxicos consumido. Quando se considera a proporção de consumo de agrotóxicos por área plantada, o fumo passa a ser a cultura que mais utiliza (6ol/ha), seguindo do algodão $(28,6 \mathrm{l} / \mathrm{ha})$ e da soja $(17,7 \mathrm{l} / \mathrm{ha})$.

Os danos à saúde humana já foram documentados em muitos estudos, tendo sido publicado um dossiê com trabalhos dos maiores especialistas do país que demonstram a gravidade dessas substâncias para a saúde e o ambiente (CARNEIRO et al., 2015). Estudos de revisão sistemática tem demonstrado a relação dos agrotóxicos com distúrbios neurológicos e alterações neurocomportamentais (MOSTAFALOU e ABDOLLAHI, 2017; GURGEL, 2017).

Os agravos à saúde mental de fumicultores são também um dos mais alarmantes do país, correspondendo à região com maior prevalência de suicídio e também que proporcionalmente mais utiliza agrotóxicos. Estudos com fumicultores tem demonstrado a relação entre a exposição a agrotóxicos e a ocorrência de transtornos mentais (CAMPOS et al., 2016; FARIA et al., 2014; CARGNIN, 2013; POLETTO, 2009; CEZAR-VAZ et al., 2016) e suicídio (FALK et al., 1996; MENEGUEL et al., 2004; KRAWCZYK et al., 2014; Cruz, 2014). Também foram descritas correlações entre agrotóxicos e risco de suicídio e transtornos mentais 
em outras culturas com expressivo uso de agrotóxicos (LEVIGARD e ROZEMBERG, 2004; CHRISMAN, 2012; MEYER et al., 2014; PAZ DE LIMA, 2008; ARAÚJO et al., 2007; PIRES, CALDAS, RECENA, 2007; ARAÚJO, GRÉGGIO, PINHEIRO, 2013; FARIA, FASSA, MEUCCI, 2014; CONTI et al., 2017; MORIN, 2016).

As alterações neurocomportamentais causadas por essas substâncias, principalmente organofosforados, piretróides e neonicotinóides são apontadas na maioria dos estudos como possível base empírica para demonstração da relação com transtornos mentais e desses com o suicídio. Se por um lado, são verdadeiras tais constatações, elas sozinhas não são suficientes para explicação dos altos índices de suicídio entre trabalhadores rurais, principalmente entre fumicultores. O estudo pioneiro de Falk et al. (1996) sobre o suicídio desses trabalhadores em Venâncio Aires (RS), corroborado por inúmeras pesquisas, principalmente por Werlang (2013), Castro (2013), Cruz (2014) e Moura (2016), mostram que os agrotóxicos são um dos fatores relacionados às muitas e intensas alterações provocadas no modo de vida desses trabalhadores a partir do atrelamento de sua produção à exploração da indústria agroexportadora.

As alterações dos modos de vida que resultam na perda de conhecimentos tradicionais do cuidado com a terra (PIGNATTI e CASTRO, 2010) e a adesão à ideia de que "só se planta com veneno", leva esses pequenos produtores a utilizarem agrotóxicos em suas plantações, sem noção dos riscos que correm e sem equipamentos de proteção que atenuem os danos, expondo-se desde a infância a intoxicações, muitas delas crônicas que resultam em comprometimento orgânico e neuropsicológico (ARAÚJO et al., 2007; CAMPOS et al., 2016; ARAÚJO, GREGGIO e PINHEIRO, 2013), limitação das capacidades funcionais, tornando o trabalho ainda mais penoso. Além disso, há uma imposição explícita do uso de agrotóxicos pela indústria do fumo e pelos bancos que condicionam o acesso ao crédito à utilização dessas substâncias, por meio do "pacote tecnológico" imposto pelos contratos (CASTRO, 2013; FALK et al., 1996).

\section{Considerações finais}

Os dados das pesquisas apontam para alta prevalência de agravos à saúde mental dos trabalhadores rurais, sendo maiores que entre a população urbana, mostrando a importância de se considerar tal dimensão nas ações de atenção à saúde no campo. Os agravos pesquisados nos estudos foram suicídio, transtornos mentais comuns (TMC), depressão, ansiedade, estresse e sofrimento difuso, além de doenças orgânicas resultantes do intenso desgaste físico e psicológico relacionados ao trabalho.

As condições precárias de vida, trabalho e seus efeitos sobre as relações sociais, além da omissão do Estado são interconectados pela lógica de exploração do capital-imperialismo nos países latino-americanos, intensificada por sua forma neoliberal de mercantilização de todas as dimensões da vida e ausência de políticas sociais voltadas para melhoria (FONTES, 2010). As alterações produzidas no processo de trabalho a partir da reestruturação produtiva e modernização conservadora da agricultura, destacadas nos processos globais incidem sobre a organização e condições de trabalho e os modos de vida dos trabalhadores rurais, tornando-os mais vulneráveis ao adoecimento.

Os estudos revisados permitem constatar que uma das categorias mais importantes para se pensar a saúde mental no trabalho rural envolve o grau de au- 
tonomia/soberania dos trabalhadores e das trabalhadoras no processo de metabolismo com a natureza para produção de suas condições de existência, sobretudo no que diz respeito ao acesso à terra, aos instrumentos de trabalho que facilitem o processo produtivo, poder de decisão sobre os ritmos, intensidade e tempo dedicado ao trabalho, equidade nas relações de gênero e raciais, de modo a compensar o desgaste natural e abrir espaço para momentos de lazer e fruição da vida. Constata-se, por outro lado, as barreiras para a saúde quando a propriedade da terra e dos meios de produção não garante a autonomia, sobretudo quando o trabalho é organizado para atender as exigências de acumulação da agroindústria, deixando os produtores apenas com o sonho do enriquecimento enquanto se configuram como trabalhadores terceirizados das mesmas.

A violência do colonizador contra os povos originários, a expropriação de suas terras, genocídio e/ou desmonte de seus modos de vida, a alta concentração de terras nas mãos de poucos (latifúndio), a dominação masculina e a escravização e negação da humanidade dos povos africanos são elementos estruturantes da sociedade brasileira desde seus primórdios. Contemporaneamente, atrelados ao capitalismo monopolista mundializado, os herdeiros desse processo expropriador, racista e patriarcal, ainda trazem suas marcas nas formas de territorialização-desterritorialização-reterritorialização do campo brasileiro, aprofundando as enormes desigualdades sociais e a precariedade das condições de vida e trabalho da classe trabalhadora rural (WERLANG, 2009).

Os efeitos psicológicos resultantes de uma vida marcada pela tensão, risco de morte, risco de perder a terra, não ter onde plantar, pescar ou coletar para garantir a própria subsistência, ter que ir a lugares estranhos vender a força de trabalho em troca da sobrevivência biológica, entre outros efeitos, produz um empobrecimento das experiências de vida, uma redução nas potencialidades dos sujeitos expropriados da liberdade de projetar e ter controle sobre a própria existência. Eis um dos retratos contemporâneos da alienação: esta não ocorre apenas quando o trabalhador não se reconhece na mercadoria produzida por ele próprio; antes, ele não se reconhece no lugar onde mora (muitas vezes de aluguel) e todas as transformações porque passa seu território são para alimentar um processo estranho à vida humana, indo muitas vezes contra ela.

Recebido em 11 de fevereiro de 2020.

Aceito em 8 de agosto de 2020.

\title{
Referências
}

\author{
ALMUSSA, A. Um Estudo Das Condições De Vida E De Trabalho E Sua Relação \\ Com A Saúde Entre Trabalhadores Rurais Do Município De Sertãozinho/Sp. \\ 2011. Dissertação de Mestrado, Psicologia, UNESP, 2011. \\ ALVES, M. C.; JESUS, J. P. de; SCHOLZ, D. Paradigma da afrocentricidade e uma \\ nova concepção de humanidade em saúde coletiva: reflexões sobre a relação entre \\ saúde mental e racismo. Saúde debate, 39 (106): 869-880, 2015.
}


ARAÚJO, A. J. de; LIMA, J. S. de; MOREIRA, J. C.; JACOB, S. C.; SOARES, M.O.; MONTEIRO, M.C.M. Exposição múltipla a agrotóxicos e efeitos à saúde: estudo transversal em amostra de 102 trabalhadores rurais, Nova Friburgo, RJ. Ciência e Saúde Coletiva, 12 (1): 115-130, 2007.

ARAÚJO, J. N. G. de; GREGGIO, M. R.; PINHEIRO, T. M. M. Agrotóxicos: a semente plantada no corpo e na mente dos trabalhadores rurais. Psicologia em Revista, 19 (3): 389-406, 2013.

BREILH, J. Entrevista. Trabalho, Educação e Saúde. 13 (2): 533-540, 2015.

BREILH, J. Nuevo modelo de acumulación y agroindustria: las implicaciones ecológicas y epidemiológicas de la floricultura en Ecuador. Ciência e Saúde Coletiva, 12 (1): 91-104, 2007.

BREILH, Jaime. Epidemiologia Crítica: ciência emancipadora e interculturalidade. Rio de Janeiro: Editora Fiocruz, 2015.

BÜHLER, Eve Anne; GUIBERT, Martine; OLIVEIRA, Valter Lúcio de. Agriculturas empresariais e espaços rurais na globalização: abordagens a partir da América do Sul. Porto Alegre: Editora UFRGS, 2016.

CAMPOS, É. et al. Exposure to pesticides and mental disorders in a rural population of Southern Brazil. NeuroToxicology, 56 (1): 7-16, 2016.

CARGNIN, Marcia Casaril Dos Santos. Perfil demográfico, socioeconômico e de saúde das famílias de fumicultores de um município da região sul do Brasil. Dissertação de Mestrado, Enfermagem, UFRGS, 2013.

CASTRO, LAURA SILVA PEIXOTO DE. Precarização da organização do trabalho: vivências de prazer e sofrimento no cultivo do fumo. Dissertação de Mestrado, Psicologia, Unisinos, 2013.

CEZAR-VAZ, Marta Regina; BONOW, Clarice Alves; MELLO, Marlise Capa Verde Almeida de; SILVA, Mara Regina Santos da. Abordagem socioambiental na enfermagem: focalizando o trabalho rural e uso de agrotóxicos. Revista Brasileira de Enfermagem, 6 (69): 1179-1187, 2016.

CEZAR-VAZ, Marta Regina; BONOW, Clarice Alves; SILVA, Mara Regina Santos da. Mental and Physical Symptoms of Female Rural Workers: Relation between Household and Rural Work. Int J Environ Res Public Health, 9 (12): 11037-49, 2015 .

CHESNAIS, F. Mundialização: o capital financeiro no comando. Outubro Revista, 24 (1): 7-28, 2001.

CHRISMAN, JULIANA DE REZENDE. Mortalidade em agricultores residentes em microrregiões produtoras de soja no Brasil. Tese de Doutorado, Saúde Pública e Meio Ambiente, FIOCRUZ, 2012.

CONTI, C. L.; BARBOSA, W. M.; SIMÃO, J. B. P.; ÁLVARES-DA-SILVA, A. M. Pesticide exposure, tobacco use, poor self-perceived health and presence of chronic disease are determinants of depressive symptoms among coffee growers from Southeast Brazil. Psychiatry Res., 260 (1): 187-192, 2016.

COSTA, M. G. S. G. Gênero, trabalho e saúde mental entre trabalhadoras rurais assentadas na região do Mato Grande Potiguar. Dissertação de Mestrado, Psicologia, UFRN, 2014. 
COSTA, P. F. F. Invisibilidade no verde dos Canaviais: Trabalho, Migração e Saúde Mental. Dissertação de Mestrado, Saúde Coletiva, UFPE, 2015.

CRUZ, Claudia Weyne. As múltiplas mortes de si: Suicídio de idosos no Sul do Brasil. Tese de Doutorado, Ciências Sociais, Unisinos, 2014.

DAL CASTEL, V. L. O silêncio dos silenciados: a desproteção social dos trabalhadores rurais. Tese de Doutorado, Serviço Social, UFRGS, 2007.

DUARTE, Guilherme José. Transtornos Mentais Comuns em Trabalhadores Rurais no Corte da Cana-de-açúcar. Santa Helena de Goiás/Goiás. Dissertação de Mestrado, Ciências Ambientais e Saúde, PUC Goiás, 2010.

ELIAS, Denise. "Reestruturação Produtiva da Agropecuária e Novas Regionalizações no Brasil”. In: ALVES, V. E. L. (org.). Modernização e Regionalização nos Cerrados do Centro-Norte do Brasil: Oeste da Bahia, Sul do Maranhão e do Piauí e Leste de Tocantins. Rio de Janeiro: Consequência, 2015. pp. 25-44.

FAKER, J. N. A cana nossa de cada dia: saúde mental e qualidade de vida em trabalhadores rurais de uma usina de álcool e açúcar de Mato Grosso Do Sul. Dissertação de Mestrado, Psicologia, Universidade Católica Dom Bosco, 2009.

FARIA, I. D. Saúde mental e trabalho rural no processo de reestruturação produtiva de uma empresa do setor sucroalcooleiro em Minas Gerais, Brasil. Dissertação de Mestrado, Saúde Pública, UFMG, 2012.

FARIA, N. M. X.; FASSA, A. G.; MEUCCI, R. D. Association between pesticide exposure and suicide rates in Brazil. NeuroToxicology, 45 (1): 355-362, 2014.

FARIA, N. M.; FASSA, A. G.; MEUCCI, R. D.; FIORI, N. S.; MIRANDA, V. I. Occupational exposure to pesticides, nicotine and minor psychiatric disorders among tobacco farmers in southern Brazil. Neurotoxicology, 45 (1): 347-54, 2014.

FAVERO, Eveline. O impacto psicossocial das secas em agricultores familiares do Rio Grande do Sul: um estudo na perspectiva da psicologia dos desastres. Tese de Doutorado, Psicologia, UFRGS, 2012.

FRANCO-BENATTI, D. de M. Acidentes de trabalho na agroindústria canavieira: circunstâncias de ocorrência e suas consequências para os trabalhadores. Tese de Doutorado, Psicologia, USP, 2016.

GALIANO, A. de Me. Trabalho rural e migração: estudo com jovens trabalhadores no corte da cana-de-açúcar na região de Ribeirão Preto-SP. Dissertação de Mestrado, Psicologia, USP, 2010.

GIONGO, Carmem Regina. Sofrimento silencioso: análise psicodinâmica do trabalho de suinocultores. Dissertação de Mestrado, Psicologia, Unisinos, 2013.

GUIMARÃES, M.C. "Só se eu arrumasse uma coluna de ferro pra aguentar mais..." - contexto de produção agrícola, custo humano do trabalho e vivências de bem estar e mal-estar entre trabalhadores rurais. Tese de Doutorado, Psicologia, UnB, 2007.

LEVIGARD, Y. E.; ROZEMBERG, B. A interpretação dos profissionais de saúde acerca das queixas de "nervos" no meio rural: uma aproximação ao problema das intoxicações por agrotóxicos. Cadernos de Saúde Pública, 20 (6): 1515-1524, 2004 . 
LIMA, J. M. M. de. Distúrbios do sono, sintomas de ansiedade e de depressão e qualidade de vida em trabalhadores rurais em período de entressafra cafeeira. Dissertação de Mestrado, Neurologia, USP, 2010.

MARX, K. O Capital: contribuição à crítica da economia política. São Paulo: Boitempo, 2013.

MENEGUEL, S. N.; VICTORA, C. G.; FARIA, N. M.; CARVALHO, L. A.; FALK, J. W. Características epidemiológicas do suicídio no Rio Grande do Sul. Revista de Saúde Pública, 38 (6): 804-810, 2004.

MÉSZÁROS, I. Para além do Capital. São Paulo: Boitempo Editorial, 2016.

MEYER, A.; KOIFMAN, S.; KOIFMAN, R. J.; MOREIRA, J. C. et al. Mood disorders hospitalizations, suicide attempts, and suicide mortality among agricultural workers and residents in an area with intensive use of pesticides in Brazil. Toxicol Environ Health A., 13-14 (73): 866-77, 2010.

MONTANARI CORRÊA M.L. É alimento ou mercadoria? Soberania Alimentar, processo de exposiçãa e imposição aos agrotóxicos e a relação alimento-saúde em municípios da Bacia do Juruena, Mato Grosso. Tese de Doutorado, Saúde Coletiva, UFMT, 2019.

MORIN, P. V. Transtornos mentais comuns em trabalhadores rurais que utilizam agrotóxicos. Dissertação de Mestrado, Atenção Integral à Saúde Instituição de Ensino, Universidade de Cruz Alta, 2016.

MOURA, R. Narrativas sobre suicídio, cultura e trabalho em um município colonizado por alemães. Tese de Doutorado, Enfermagem, UFRGS, 2016.

PAZ DE LIMA, P. J. Avaliação da qualidade de vida e transtornos mentais comuns de residentes em áreas rurais. Tese de Doutorado, Saúde Coletiva, UNICAMP, 2014.

PAZ DE LIMA, P. J. Possíveis doenças físicas e mentais relacionadas ao manuseio de agrotóxicos em atividades rurais, na região de Atibaia, SP/Brasil. Dissertação de Mestrado, Saúde Pública, USP, 2008.

PIGNATI, W. A. et al. Distribuição espacial do uso de agrotóxicos no Brasil: uma ferramenta para a Vigilância em Saúde. Ciênc. saúde coletiva, 22 (10): 32813293, 2017.

PIGNATTI, M. G.; CASTRO, S. P. A fragilidade/resistência da vida humana em comunidades rurais do Pantanal Mato-Grossense (MT, Brasil). Ciênc. saúde coletiva, 15 (supl. 2): 3221-3232, 2010.

PINHEIRO, C. R. Química da enxada: transformações do trabalho no campo, uso de agrotóxicos e seus impactos na saúde e ambiente no Acampamento Baixa Verde (MLT) - Eunápolis/BA. Dissertação de Mestrado Profissional, Saúde Pública, FIOCRUZ, 2016.

PIRES, D. X.; CALDAS, E. D.; RECENA, M. C. P. Uso de agrotóxicos e suicídios no Estado do Mato Grosso do Sul, Brasil. Cadernos de Saúde Pública, 21 (2): 598605, 2005.

PISTORIO, Bianca Vasquez. Sofrimento Social de Trabalhadores Rurais Assentados na Contracorrente do Agronegócio. Dissertação de Mestrado, Saúde Coletiva, UFMT, 2017. 
POLETTO, A. R. Processo de trabalho e saúde mental de trabalhadores agrícolas familiares da microrregião de Ituporanga, Santa Catarina. Tese de Doutorado, Engenharia De Produção, UFSC, 2009.

PRIULI, Roseana Mara Aredes; MORAES, Maria Silvia de; CHIARAVALLOTI, Rafael Morais. Impacto do estresse na saúde de cortadores de cana. Rev Saúde Pública, 48 (2): 225-231, 2014.

ROTHER, Edna Terezinha. Revisão sistemática X revisão narrativa. Acta paul. enferm., 20 (2): v-vi, 2007.

RUMIN, C. R.; NAVARRO, V. L.; PERIOTO, N. W. Trabalho e saúde no agrobusiness paulista: estudo com colhedores manuais de cana-de-açúcar da região oeste do Estado de São Paulo. Cad psicol. soc. Trab., 11 (2): 193-207, 2008.

SANTOS, M. de L. P. dos. Saúde mental de trabalhadores da agricultura familiar inseridos no programa nacional de produção e distribuição do biodieselPNPB de uma cooperativa da Bahia. Dissertação de Mestrado Profissional, Bioenergia, Faculdade de Tecnologia e Ciências, 2013.

TONET, M. S. O trabalho de agricultoras e o processo de produção de saúde/adoecimento. Dissertação de Mestrado, Promoção Da Saúde, Universidade de Santa Cruz Do Sul, 2015.

VERÇOZA, L. V. de. Os saltos do "canguru" nos canaviais alagoanos. Um estudo sobre trabalho e saúde. Tese de Doutorado, Sociologia, UFSCar, 2016.

WERLANG, R. Pra que mexer nisso: Suicídio e sofrimento social no meio rural. Tese de Doutorado, Psicologia Social e Institucional, UFRGS, 2013. 


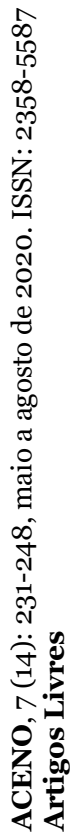

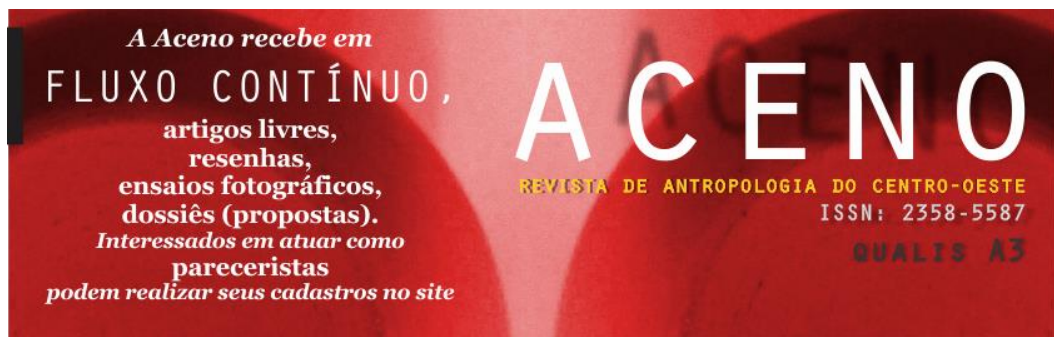

